\title{
Egyptian Workers in Paris - Economic Migration and the Male Burden under Transnationalism
}

By REem SAAD

This article looks at the living and working conditions of a group of Egyptian workers in the Paris region. The article argues that the experience of this group is dictated by a transnational framework that is particularly evident in the meanings of 'community' and of 'home', and by the gender assigned roles in ruval Egypt where the man is to shoulder the burden of providing for the family.

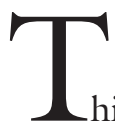

his article presents a case studyl of a group of Egyptian labour migrants in Paris originating from the Gharbiya village of Mit Badr Halawa. This village boasts a large number of clandestine workers living in France who work mainly in the construction sector and in the weekly food markets of Paris. The reason for migration of this group is to be understood in the context of the now chronic problem of unemployment in rural Egypt. With diminishing possibilities for travelling to Arab countries, travel to Europe has recently become a very attractive option, especially among young men with an intermediatelevel education.

This group of labour migrants, who are motivated primarily by economic considerations and who send remittances home to help their families survive and improve living conditions, could arguably be studied within a conventional paradigm of international migration as has been the case with their 'predecessors', who migrated to oil- 
rich Arab countries from the late 1970s to the early 1990s. This is especially true since the two groups (or waves) share many similarities in terms of motivations, work opportunities and living conditions in the receiving countries. It is, however, the aim of this article to show that the intensity of network activity, as well as the multiple strands that constitute them, are defined by a transnational framework in which 'origin' and 'destination' are a single social field. As a result, I adopt the definition of transnationalism proposed by Basch, Schiller and Blanc, who see it as "... the processes by which immigrants forge and sustain multistranded social relations that link together their societies of origin and settlement" and that "(t)ransmigrants take actions, make decisions, and develop subjectivities and identities embedded in networks of relationships that connect them simultaneously to two or more nation-states" (Basch, Schiller \& Blanc 2000, 7, emphasis added). This is a group which displays a high degree of simultaneity, where decisions, interests and indeed most aspects of life are carried out within networks that span the two worlds. While simultaneity is often seen as a primary obstacle preventing integration, ${ }^{2}$ I focus on its role as an instrument for perpetuating the flow of migrants and reinforcing the existence of Badrawis (which people from Mit Badr Halawa are known as) as a strong group.

One important feature of this type of migration is that we are dealing with an allmale world. The gender dimension of this feature is readily visible in the accommodation, work and recreation activities of labour migrants in Paris. The meaning of the migration experience and its implications for the individual migrant, however, cannot be fully understood without reference to gender roles in rural Egypt. In particular, it must be remembered that the distinction between the worlds of men and women along a public/private duality is, for the most part, a feature of the social re- ality rather than a result of the bias of male researchers who failed to take into account the women's point of view, as has been argued in a number of studies (Abu Lughod 1986, 29-30, Mitchell 1990, 242-243, Morsy 1988, 78, Nelson 1991, 133-136). A related issue is that culturally assigned gender roles and responsibilities in rural Egypt place the burden of providing for the family on the man, and that the successful fulfilment of this role is a major defining attribute of a 'real man'. In this case, I draw on research covering manhood and masculinity, particularly the view that there are a variety of types and styles of manhood, even within the same society (Loizos 1994, Kandiyoti 1994).

In the following, I draw a preliminary map delineating the characteristics of this group, the types of networks that span their lives in Paris and in Egypt and the gender implications of the migration experience. I particularly focus on two areas where the transnational dimension is most evident, namely in the meanings of 'community' and 'home' under transnationalism.

\section{METHODOLOGY AND FIELDWORK}

This research project relied exclusively on qualitative methods, mainly participant observation and in-depth interviews. Interviews were conducted in the men's homes and in public places, especially cafés. ${ }^{3} \mathrm{Ob}$ serving and interviewing the men at their places of work was only possible at the various weekly markets in Paris due to their accessibility and because they are open public spaces. The other main workplaces for the target group involved building and construction sites, where access was not easy mainly because my informants felt uncomfortable having a researcher present.

The majority of the fieldwork was conducted in 2004-2005 and included a oneday trip to the village of Mit Badr Halawa in May 2004. The purpose of the trip was to deliver letters to the families of two of 
my key informants and to take pictures and video shots of certain people and sites in the village that the people in Paris wanted to see.

It is important to mention that a number of issues relevant to this research could be potentially incriminating. Thus, informants were generally justified in their reluctance to discuss, for example, 'new' ways of arriving in France, or ways of transferring money to their village. In cases when they were forthcoming with information, I did exercise a degree of censorship to avoid the possibility of incurring any harm to my informants.

\section{EgYPTIANS IN PARIS:}

\section{THE OFFICIAL FRAMEWORK}

The most obvious problem any research of this type faces is the lack of reliable (and even unreliable) data. This is mainly due to the fact that we are dealing with mostly clandestine migrants, who, by definition, are not registered. The information available based on official national statistics pertains mainly to permanent legal migration, and estimates the number of Egyptians in France at 36,000.4 The reliability and usefulness of this figure is contested even by Egyptian officials. 5 The Egyptian Consul General in Paris, Ambassador Nahed AlAshry, explains in a personal communiqué that this figure is greatly underestimated, and that the number could not possibly be less than 60,000 and that she estimates it to be around 100,000. The official figures are derived from consulate registers which only counts voluntary registrations. Ambassador Al-Ashry sees that a long tradition of mistrust has characterised the relationship between Egyptian citizens and their consulate. Among her top priorities when she assumed office in 2002 was to work towards gaining trust and building stronger links with the Egyptian community in France. She published an appeal in the Egyptian daily $A l$-Akbbar, one of the most popular newspapers, strongly urging Egyptian citizens to register with the consulate in order to benefit from the backing and support of their government. This appeal was addressed to those with and without legal status. She then initiated and hosted a series of meetings with 'the Egyptian community', which resulted in the formation of an 'Association for the Egyptian Community in France'. 6

This type of reaching out is commendable and, in many ways, unprecedented. However, people without legal status understandably will never register anywhere, especially with their consulate. An illegal immigrant's worst fear is deportation, a long, complicated process that cannot be finalised unless the nationality of the deportee is established. As a result, illegal immigrants (of all nationalities) either get rid of or hide their passports so that their nationalities cannot be identified. In cases where arrests are made, the person is referred to the consulate of their suspected nationality. If that person is registered with the consulate, then evidence of nationality exists and deportation becomes inevitable.

\section{The Place of Mit Badr HalaWA}

It is similarly impossible to know the number of Badrawis, whose estimate of their number is most probably highly exaggerated. A figure they often mention is $4,000,{ }^{7}$ which does not seem reasonable given that the total population of the village is 16,813 (CAPMAS 1996). The belief that they are "everywhere" comes from their visibility and increasing monopoly over certain jobs, especially in the construction industry and in the weekly food markets. Moreover, the normal (or rather ideal) career trajectory of young men in the village is to migrate or try to migrate to France, which then gives the impression that "half of Mit Badr is here".

In addition, the exaggerated estimate of their numbers by the Badrawis may be re- 
lated to the perceived impact Mit Badr has on other places in Egypt. Probably the first labour migrants to arrive in France, the Badrawis believe they have paved the way for other Egyptians to follow course. The Badrawis think they are the reason for an increasing number of Egyptians in France, and that they are responsible for the fact the number of Egyptians is now comparable to that of other Arabs (Tunisians, Algerians and Moroccans). While this sentiment may be exaggerated, it is true that Mit Badr occupies a special place within the Egyptian community in Paris.

Apart from Mit Badr, there are a number of other Delta villages whose names recur very often in this regard, although Mit Badr remains the most prominent. ${ }^{8} \mathrm{Mi}-$ grants from the Delta village of Sibrbay have been studied by Detlef Müller-Mahn. My findings on the networks of the Badrawis and the dynamics of life in the transnational space are very much in line with Müller-Mahn's analysis. ${ }^{9}$

The group I am dealing with is distinguished by the purpose of its migration, which is to work to make money mainly to be used to improve one's (and one's family's) living conditions at home. The typical profile of members of the most recent wave of clandestine economic migrants is that they are young men with an intermediatelevel education with some training, usually in building and construction work.

An earlier group of Badrawis possess legal residency documents, mostly through marriage to a French national. Members of this group play a crucial role as mediators between the illegal migrants and French society. Their legal status qualifies them to become 'patrons', or bosses, allowing them to head businesses either in the market or in the construction industry, where they, in turn, are the primary employers of their fellow villagers.

\section{NeTwOrKs AND COMMUNITIES}

One main attribute of the migration enterprise is that the young men who cross the Mediterranean do not embark on this undertaking as isolated individuals but as a member of a family and other networks both in Egypt and in France.

It is almost a truism to say that social networks are important among immigrants. Networks of course exist and always have. What concerns us here is the connection between transnational networks on the one hand, and the new meanings and practices of 'community' on the other. As Ulf Hannerz argues,

'Transnational communities' is not a contradiction in terms. This is a matter of kinship and friendship, of leisure pursuits, and of occupational and corporate communities. What is personal, primary, small scale, is not necessarily narrowly confined in space... (Hannerz 1996, 98).

Kennedy and Roudometof argue that one important way in which transnational connections impacted the nature of community is the diminishing importance of locality "as the only or even the primary vehicle for sustaining community" (Kennedy \& Roudometof 2002, 13). They see that transnational communities survive through experiencing locality symbolically in the form of "nostalgia, memory, history or constructed cultural sites" (Kennedy \& Roudometof 2002, 25). In the following, I describe three types of networks that the Badrawis are involved in and the ways in which 'community' is understood and/or practiced in each case.

\section{The all-Egypt network}

The most formalised version of the allEgypt network is the recently launched "Association of the Egyptian Community in France" (Rabitat al-Galiyya al-Misriyya fi Faransa), an organisation that resulted from the initiative of Ambassador Nahed 
Al-Ashri, the Egyptian Consul General in France (Al-Ahram April 11, 2005). According to her, the purpose of this association is to enhance the power of the Egyptian community within French society, as well as in Egypt. The association started its activities about two years before its formal launching, during which time it generally focused on issues relating to the question of Egyptian integration into French society, as well as issues of concern to the settled Egyptian community, such as the establishment of an Egyptian school.

This network with its concern for matters of cultural and national identity supports a community based solely on a shared feeling of national belonging. While Saleh Farhoud, the elected president of this association, is a prominent figure from Mit Badr Halawa, ${ }^{10}$ this type of institution and its networking functions are not the most relevant for the group we are dealing with, i.e. people whose often clandestine status keeps them away from any official connections. More importantly perhaps, their concerns tend to be immediate and practical, like finding accommodations and work. For them, other types of organisations and networks are more important. I will present the case of a semi-formal institution that serves as a focus (and locus) of strong network links among Egyptian workers in Paris: The Association of the Sons of Gharbiyya Governorate, which is actually a café located in Simplon that is rented and operated by a man from Mit Badr.

Although surrounded by many cafés, this one is not to be compared to the mushrooming Egyptian cafés in central Paris, which are a new fad on the capital's entertainment scene and are frequented mainly by Parisian youth attracted to the distinctive atmosphere, who drop in for a mint tea and water pipe. The café in Simplon is a real Egyptian coffee shop (ahwa baladi), although it does not look like one. A square room lined with benches (kanaba), it resembles the guest room (mandara) of a vil- lage house rather than a coffee shop. This all-male space is mainly used for leisure in the same way as a traditional Egyptian coffee shop, including smoking water pipes, playing backgammon and watching TV. In this case, the television is always tuned into an Arabic channel, for example, the Arabic Radio and Television channel showing Egyptian movies, the Al-Jazeera news channel, or the sports channel showing an Egyptian football match. Yet it is not only a place for spending free time and getting a taste of home, it is also a place for exchanging important information (mostly about work and accommodations) and for making work-related appointments. Again, in its function as an information centre, it is no different from the traditional coffee shop at home. The cafe in Simplon is a concrete illustration of Ulf Hannerz's point concerning ordinary labour migrants, where in contrast to cosmopolitans, "a surrogate home is again created with the help of compatriots, in whose circle one becomes encapsulated" (Hannerz 1996, 106).

Egyptian labour migrants tend to cluster together in certain quarters (like Belleville and Simplon), often occupying several flats in the same building. In these types of quarters, where the concentration of Egyptian workers is high, Egyptian shops open selling Egyptian products such as tea, feta cheese, fava beans, lentils, tahina, Cleopatra cigarettes, etc. This is one readily visible clue regarding the Egyptian workers' lifestyle, where they try as much as possible to stick to a world that is familiar.

The Cairene founder of the Café, Hajj Mohamed Ali, is the owner of a next-door travel agency specialising in Egypt tours. He recounts how and why this place was established:

I found that Egyptians here do not have any place to resort to. I thought of having a place where they can get together. In the year 2000 , I initiated the founding of an association to look after the affairs of Egyptians 
here. We called it "The Association of the Sons of Gharbiyya Governorate", because most people here come from that governorate. It turned into this meeting place where Egyptian youth meet. Anyone who needs work can find work, as all the "bosses" hang out here. We thought that other governorates would follow suit and establish their own meeting places. But, instead, everybody started to meet here, including people from Sharkiyya, Assyut and Alexandria.

Interestingly, the Hajj emphasises a moral dimension about this place, as it keeps Egyptian youth away from the temptations offered by French society, especially those that may be in contradiction with the principles of Arab morality. Hajj adds:

This place does not serve alcohol. It is impossible to have people praying here and others drinking alcohol next to them. The main aim of having this place is to keep our youth off the streets. If they do not come here, where will they go? They may go chase women or go to a French café where they would be dealing with other types of people. If they have no money, they may go begging. But here, they can find work if they have no work or a place to live.

The consulate-based association and the association-based café support different types of mobilisation and networking towards specific ends. However, the greatest majority of the network-based exchange of support and information are not institutionalised but spontaneous and ad-hoc. The most pertinent example of the mobilisation of Egyptians is in the event of the death of an Egyptian. When this happens, the consulate pays for the repatriation of the body. However, a group of Egyptians often mobilises to collect money to pay the airfare for someone to accompany the body to Egypt. They also send a sum of money to the family of the deceased in Egypt, which is apparently a common and standard prac- tice. The sums collected are substantial, with figures ranging from 5,000 to 10,000 Euros.

\section{The Mit Badr network}

The Mit Badr network, which is also about information concerning work and accommodations, is also about obligations towards the village in general. The name of this village is always associated with the idea of the loyalty of its people, mainly because the Badrawis in Paris have shouldered a number of projects in the village, the most important of which was initiating the establishment of a sewage system, in addition to building a school and a health centre. This is an area where the transnational nature of this community is most apparent, as the meaning and significance of the Badrawis' services to their village lies in the transnational space that spans their two worlds. This type of activity signals, simultaneously, the special place that Mit Badr occupies in both Paris and in the Delta region in Egypt. It also signals a confirmation that Mit Badr is 'home', a place where displaying the success of the mission behind migrating is most meaningful. This is a point that Bruno Riccio makes concerning the Senegalese transnational organisations of migrants in Italy "competing for the construction of public services at home" (Riccio 2002, 81). It is significant that the previous mayor of the village used to make special trips to Paris in order to collect money from the Badrawis for these matters.

The most prominent project carried out by the Badrawis in Paris for their village was financing the construction of a sewage system. A committee in Paris aided by a visit from the mayor of Mit Badr was responsible for collecting the money. According to a member of the committee, the biggest part of the payment was imposed on the 'patrons' (business owners), while others made payments according to their abilities. The project was only partly realised due to administrative complications, but the rest 
of the money remains in a special bank account in Egypt. The transnational nature of the Badrawi community in Paris is evident in the way that gaining prominence in the village and in Paris is interlinked. The leadership of the community in Paris (the Shaker familyll) and their active role in organising funding for the sewage system translates into prestige in the village and vice versa.

\section{The family-based network}

A reason often cited for the large number of Badrawis in Paris is "jealousy among the families" in the village itself, referring to the social structure of the village being built around the existence of a number of large families. It is at the level of the family that most activities relating to the migration process take place. Nicholas Van Hear argues that "The transnational community includes the people at home who are integral to it. The members of the 'community' in question are those at home as much as those abroad" (Van Hear 2002, 221). This statement applies in particular at the level of the family.

The family-based network is the context of and facilitator in a number of key areas. For example, sponsoring newcomers is the most important activity that takes place on the level of the family. This practice is not only responsible for the steady flow of newcomers, but also for the increasing strength and magnitude of the Badrawi community in Paris. The ability to bring more family members is a matter of pride and an indication of a family's power. ${ }^{12}$

The decision about whose turn it is to travel is made at the level of the household and must balance with the equally important decision concerning who will stay to look after the affairs of the family and oversee the distribution and investment of the remittances. Family members in Paris also take part in recommending who should go next, based mainly on their evaluation of available work opportunities. They are also the ones who are responsible for covering all or some of the expenses of the journey. This practice indicates how the economic dimension is established in the kinship relationship and sponsoring a relative's journey creates a patronage bond.

What is referred to as "buying the visa" is actually a phrase that covers all of the expenses of the journey. Informants say visas are now a lot more costly than they used to be. The figure cited is between 35 to 40 thousand Egyptian pounds or even more. 13 However, they always hasten to add that people have stopped coming. This may not be the truth but this issue is too sensitive and maybe they feel they have to protect the newcomers.

Apart from paying for or contributing to covering the expenses of the trip, the family-level network in Paris arranges for work and accommodations for new arrivals, at least during the initial phases. This situation conforms to Hannerz's characterisation of this type of chain migration, where "the consequences of (the) extension of community in space.... are of a practical nature" (Hannerz 1996, 99). In the following quote, a Cairene owner of a market stall describes the way Badrawis benefit from their network of relatives at the food markets:

They know the work and they teach it to each other. For example, someone who is a longtime client of a trader in the wholesale market would take his cousin who just arrived, introduce him to the trader and ask him to give him the same treatment. Thus, someone who arrived in Paris only yesterday would have the advantage of someone who has been here for 20 years.

Another important aspect of support provided by relatives is preparing the new immigrant, even while still in Egypt, in terms of providing him with basic information that facilitates the initial stages of adaptation to living and working in France. Ahmed, who knew before he arrived that 
he would be working in the market, recounts how he was prepared:

I arrived from Egypt knowing the names of all commodities. I knew what grapes are called (in French) and what oranges are called. You also arrive here knowing the numbers up to 100, and as long as you know these numbers then you can handle money for buying and selling. Also, before I came here, I had a map of Paris, the one that has the metro lines. They had given me directions on how to get to the house if there was no one waiting for me. I hadn't even been here for 3 days and I knew how to get around on all the metro stations in Paris, and I could even change lines.

Family members in Paris have a collective obligation towards the family in the village. Fulfilling these obligations requires a high level or organisation and mobilisation, which mainly takes place in the form of collecting a monthly sum to be sent to the village. There is a committee in Paris to organise the collection and someone in the village to oversee the utilisation of this money.

Mohamed, a member of the large A. family, explains this system as follows:

There are 40 people from our family here. Each family member contributes some money, whatever he can give but no less than ten Euros each month. This money gets sent to Egypt, where three or four of the family elders determine what to do with the money. For example, if there is someone from the family who is ill, they pay for his treatment; they can designate a monthly payment to a poor widow, or contribute to the marriage expenses of a girl whose father cannot afford to pay for the wedding alone. At one point, the family needed to buy a tomb, so they used our contributions towards buying the land necessary for that. Now, they are thinking of building a guest house for the family in the village. We want to do that in the future.
This type of collective action seems to be modeled based on a tradition of collective action at the level of the family in the village. And, apart from these monthly contributions, the zakat (alms) money is collected in Paris and sent to the village to be distributed in the same way.

Last but not least, the large family provides security in the most immediate, basic and literal sense, where family members are mobilised in cases where one of them or their friends are involved in a fight. The following story is recounted by Ahmed, a Cairene who has benefited from his close connection with a Badrawi family with a large contingent in Paris:

Once someone hit my parked car. I went to talk to him, but he pushed me and summoned four of his friends. They wanted to hit me. I quickly made a phone call to my friend from Mit Badr. In a few minutes, there was a small army of 25 people from his family who arrived immediately. Here, if you say that someone from this or that family is involved in a fight, 50 people show up to help. That is why people think twice before getting on the wrong side of someone from a large family from Mit Badr.

The extent of the continuity that exists between the family in the village in Egypt on the one hand, and the family members already in Paris on the other, underlines Van Hear's point regarding the single community that encompasses those at home and those abroad. Van Hear believes this is due to the role of remittances being the "concrete, material manifestations of 'transnationalism". He also argues that "remittances should be seen as two-way exchanges", due to household investment in the migration expenses. (Van Hear 2002, 221 ). While remittances play a crucial role, the transnational connections between the Badrawis in Egypt and the Badrawis in Paris involve a lot more. The presence in Paris of a large number of family members 
has a significant impact on the nature of the transnational Badrawi family, especially in the way the community combines elements of long-distance interaction with face-to-face immediate connections.

\section{BADRAWIS AND THEIR 'HOMES'}

The transnational framework that determines the Badrawis' migration experience is most clearly seen in their relationship to 'home'. Here, I take a conceptual clue from Al-Ali and Koser, who see "the multiple allegiances to places" as a defining feature of transnational migrants, with the consequence that "the meaning of 'home'... is likely to be complex and multidimensional." (Al-Ali \& Koser 2002, 8). However, regardless of how long the Egyptian immigrant stays, he considers his stay temporary and that he will eventually go back to Egypt. This is not just something people say, but rather is significantly reflected in their plans for their and their children's future, whereby even those who have largely settled in France have still invested in building houses in their village, in addition to other investments in Egypt that mainly include real estate. The general pattern is to go back each year with the whole family. The house they built in the village, in addition to other second homes in Cairo or on the Northern coast, is intended for the use of their children. Whether or not the children will comply with their parents' plans for them is a different issue. This matter has significant implications regarding the question of the dissociation between community and locality raised earlier. Placing large investments in property and houses in their home village points to a desire to have a physical anchor there and to reunite community with locality, a situation that places some reservations on Kennedy and Roudometof's argument regarding the diminishing importance of physical locality in favour of experiencing it only symbolically $(2002,13,25)$.
The issue of the migrants' houses in their home village is a central one and is worth discussing at some length. The first step a migrant takes after repaying the debts that made his journey possible is to buy land in the village, then build a house. This, of course, is carried out by other family members in the village. This way of investing remittances has led to a great rise in property values in the village of Mit Badr Halawa. A number of the migrants' houses are huge, multi-storied buildings with very characteristic, decorative and lavish architecture. Some of the homes are painted in striking colours, have tiled roofs and facades and are enclosed by large and conspicuous ornate iron gates. There are two very different ways of talking about the changes in Mit Badr brought about by "French money". First, Badrawis generally talk of the changes in the village, especially the 'new architecture', which is regarded as a sign of progress, in positive terms. Second, people who are not from Mit Badr, particularly those who come from an older generation of migrants and who are generally more educated, are very contemptuous and cynical about the changes. This group generally regards Badrawis as peasant upstarts viewing their new architecture as a blind and distorted imitation of what the Badrawis saw in France.

The degree of contempt expressed towards Badrawis by this particular group must be seen in the context of a situation where members of the older, educated generation are now working side by side with people they deem to be of a lower status. This is particularly evident in the market place, which is witnessing an encroaching monopoly by Badrawis. ${ }^{14}$ This situation is best expressed in the following statement made by a male, university-educated Cairene who came in the late 1970s to do post-graduate studies and now owns a market stall in a predominantly Badrawi area:

Before the 1980s, the people who came to 
France were the educated class. Now it is different. The types of people who came later are fellabin. They do not compare in terms of culture, education or morals. Especially after the Gulf War, France attracted all types of people indiscriminately. And now, everyone in the market wears a "yellow suit"- like in the army - we all look the same.

In the village, a striking migrant house is, without doubt, a sign of success and a sign that this is the place the migrant considers to be home, a place where displaying one's success is most meaningful, as Bruno Riccio argues is the case with Wolof Senegalese migrants in Italy. Ruba Salih presents the case of Moroccan migrant women in Italy who, "place all their efforts in advancing their status in Morocco, independently from potential projects of permanent return" (Salih 2002, 56, m.u.). It is important to look at the lavish migrant houses with gates and striking facades as a way of investing in status markers in the place of origin. The supposedly French style of the houses inscribes the "French connection" on the face of the village, and credits the owner with the most cherished type of symbolic capital in Mit Badr, namely success in France. This aspect is very similar to how Riccio describes Wolof Senegalese transmigrants in Italy and the high status value they placed on multi-storey buildings in their village (Riccio 2002, 81). There is, however, an added dimension because status symbols in the village reflect directly on the status of the transmigrant, adding to the strength of his family in Paris. This is particularly significant in the case of the patrons who are semi-integrated due to their legal status, which allows them to go back and forth, and who have, in most cases, started families in France. Aspects of symbolic capital and status markers not only apply equally successfully in both places, but they are effective precisely because they operate in the transnational space that encompasses both places.

\section{HARDSHIP AND VULNERABILITY}

The harshest problem clandestine labour migrants face is their inability to go back and forth, which is not possible for two main reasons. One reason is that the risk and expense involved in coming to France would then have been wasted once they leave. The other problem is that most of the young men (under 30) living in France have not yet performed their military service. Once they reach the age of 30, they can pay a fine to settle this issue, but before then, they cannot travel freely. These two obstacles to visiting home intensify the feelings of ghurba (estrangement), and make the feelings of hardship and self-pity more acute. Migrant accounts of their experience are filled with a sad and emotional tone. In general, they stress their vulnerability and are particularly keen to convey the message that they are neither happy nor comfortable in France. This sentiment is linked to the fact that the presence of migrant labourers in France is partly due to the family's decision and collective interest. Young men actually yearn to get the chance to travel. Yet, they never admit that moving was their choice, or desire, but they justify the journey by saying they were pushed into doing it by others in the family. Part of the explanation and justification for leaving is to comply with the wishes of family elders and to shoulder the responsibility for other family members, be they younger siblings, elderly parents, or sisters who need to marry. This dynamic is what makes stories of hardship and vulnerability compatible with ideals of manhood, for, in this case, what is stressed is the man's obligation as the breadwinner of the family. For example, the fact that men have to cook and clean the house implies a gender role reversal that would be shameful in the village context. In the migration context, however, this is seen as part of the burden of being a provider, which is an attribute of a real man. ${ }^{15}$ This is one sense in which (the dependent) family serves to cast a noble light 
on experiences that would otherwise seem socially costly and compromising. An important notion here is that of akl 'eish (earning daily bread), which denotes a powerful imperative and is almost always used in association with the amount of sacrifice and what one has endured or given up in order to meet that imperative. ${ }^{16}$

\section{CONCLUSION}

In the preceding discussion, I have tried to provide an outline of and explanation for certain features of a particular community of Egyptian workers in Paris. The Mit Badr group admittedly has special and sometimes unique characteristics. At the same time, it shares a lot of features with the larger community of Egyptian workers regardless of their origin or regional affiliation. The Egyptian workers, for their part, are very similar to immigrant workers of other nationalities who, in many ways, are in a similar position.

One aspect that I was particularly keen to show is the very close link that exists between the village of Mit Badr Halawa in Egypt and the Badrawi community in Paris. In other words, this is a group that displays a high degree of simultaneity, i.e. of being 'here' and 'there'. This simultaneity is effected in the transnational space of networks and is the main instrument for the reproduction of this particular type of transnational existence. The transnational nature of this group is particularly apparent in the multiple networks in which they are enmeshed. These networks, in turn, support multiple meanings and practices of 'community'. Most significantly, the transnational framework and the simultaneity that characterises the experience of this group produce communities that range from the 'imagined community', with an emphasis on elements such as memory, nostalgia and bonds of national belonging, to communities that are based on immediate face-to-face relationships.
The other main area where transnationalism defines the experience of this group is in their relationship to 'home'. Badrawis consider their village of origin as their home, the place where their primary loyalties lie, and where they invest heavily in obvious markers of success, especially the lavish, multi-storey houses. The supposedly French-looking buildings signal the success of the migration enterprise. The symbolic capital acquired is equally effective in the village and within the Badrawi community in aris because a single social field spans the two worlds.

\section{Notes}

1. The research on which this study is based was supported by the Development Research Centre on Migration, Globalization and Poverty at the University Of Sussex, which is funded by DFID, as well as by the Social Research Center and Forced Migration and Refugees Studies Program at the American University in Cairo. Thanks go to the above institutions as well as all my informants in Paris, and especially to my husband Nasseif Azmy. 2. On the importance of this issue in French society, see Duchesne 2003.

3 . Henrietta Moore makes this point regarding anthropological studies on gender in general, “...recent work in anthropology has demonstrated that cultures do not have a single model of gender or a single gender system but rather a multiplicity of discourses on gender... $(1994,55)$.

4. I conducted fieldwork accompanied by my husband Nasseif Azmy, a social worker and artist living and working in Paris. He produced a video document on the subject as part of the same research project.

5. Central Agency of Mobilization and Statistics. Quoted in: "Why Do Migrants Leave their Countries" (2003).

6. A report issued under the auspices of the Ministry of Manpower and Emigration questions, in particular, "the reliability of national estimates regarding the total number of Egyptians abroad, especially those related to the permanent or semipermanent migrants who migrate to non-Arab countries" (Contemporary Egyptian Migration 2003, 36). A similar point is made by Ayman Zohry and Harrell-Bond (2003, 18-19). 
7. Interview with Her Excellency Mrs. Nahed alAshri, Egyptian Consul General in Paris, 9 December 2004 .

8 . This is also the figure quoted in a newspaper story on Egyptian migration to Europe (Al-Ahram 19 April 2004).

9. For example, in an article in the official daily $A l$ Abram on labour migration to Europe, Mit Badr Halawa is singled out as an example of a village exporting its men to France ("Travellers without return”, Al-Abram 19 April 2004).

10. I subscribe to the usage of 'space' adopted by Müller-Mahn, who, following Bourdieu, sees it as a "metaphor for social networks" (Müller-Mahn 2005, 1).

11. We tried several times to get an appointment to interview Mr. Farhoud, but it was not possible.

12. This is a pseudonym.

13. This type or level of network is best described in a study by Baur and Gang on networks and migration: "Beneficial network externalities arise when previous migrants provide shelter and work, assistance in obtaining credit, and/or generally reduce the stress of relocation to a foreign culture... These personal connections provide potential migrants with information about the labor market in the host country. They offer important data that work to mitigate imperfect information about the labor market in the host country, enabling the migrant to obtain better paid and more stable jobs." (Baur and Gang 2002, 1).

14. Egyptian authorities arrested members of a ring specialising in trafficking Egyptian and Asian youth to Europe from the Egyptian coast using fishing boats. The fee quoted for the trip is between 30 and 40 Egyptian pounds, i.e. a figure very similar to that reported by my informants (Al-Ahram 23 May 2005).

15. Detlef Müller-Mahn (2000) discusses the dominance of Badrawis in the Belleville market (Translation from German courtesy of Nicholas Hopkins).

16. See Gilmore on the shame associated with men who cook in Andalusia (1990, 54-55).

17. For more details on manhood, labour migration and vulnerability, see Saad 2000.

\section{REFERENCES}

\section{- Abu-Lughod, Lila (1986): Veiled Sentiments.} University of California Press, Berkeley.

. Al-Ali, Nadje \& Koser, Khalid (2002): "Transnationalism, International Migration and Home", in Nadje Al-Ali \& Khalid Koser (eds.): New Ap- proaches to Migration? Transnational Communities and the Transformation of Home. Routledge, London and New York.

- Basch, Linda; Schiller, Nina Glick \& Szanton Blanc, Cristina (2000): Nations Unbound: Transnational Projects, Postcolonial Predicaments and Deterritorialized Nation-States. Gordon and Breach Science Publishers, Amsterdam.

- Baur, Thomas \& Gang, Ira (2002): "Networks and the Duration of Temporary Migration". Ministry of Manpower and Emigration: Emigration and Egyptians Abroad Sector, http://www.emigration.gov.eg/publications/Publ ication.asp

- Central Agency for Public Mobilisation and Statistics (1996): 1996 General Census, Cairo

. Contemporary Egyptian Migration (2003): Ministry of Manpower and Emigration and International Organisation for Migration, http://www.emigration.gov.eg/StaticFiles/Publication/Contemporary_Egyptian_Migration.pdf <http://www.emigration.gov.eg/StaticFiles/Publication/Contemporary_Egyptian_Migration.pdf - Duchesne, Sophie (2003): "French Representations of Citizenship and Immigrants: The Political Dimension of the Civic Link", in Immigrants and Minorities 2003/22.

- Gilmore, David (1990): Manhood in the Making: Cultural Concepts of Masculinity. Yale University Press, New Haven and London.

- Hannerz, Ulf (1996): Transnational Connections: Culture, People, Places. Routledge, London and New York.

- Kandiyoti, Deniz (1994): "The Paradoxes of Masculinity: Some Thoughts on Segregated Societies", in Andrea Cornwall \& Nancy Lindisfarne (eds): Dislocating Masculinity: Comparative Ethnographies. Routledge, London and New York.

- Kennedy, Paul \& Roudometof, Victor (2002):

"Transnationalism in a Global Age", in Paul Kennedy \& Victor Roudometof (eds.): Communities across Borders: New Immigrants and Transnational Cultures. Routledge, London and New York. - Loizos, Peter (1994): “A Broken Mirror: Masculine Sexuality in Greek Ethnography", in Andrea Cornwall \& Nancy Lindisfarne (eds.): Dislocating Masculinity: Comparative Ethnographies. Routledge, London and New York.

- Mitchell, Timothy (1990): "Everyday Metaphors of Power", in Theory and Society 1990/19.

- Moore, Henrietta (1994): A Passion for Difference. Polity Press, Cambridge.

- Morsy, Soheir (1988): "Fieldwork in My Egyptian Homeland", in Soraya Altorki \& Camillia F. El-Solh (eds.): Arab Women in the Field: Studying 
Your Own Society. Syracuse University Press, Syracuse.

· Müller-Mahn, Detlef (2000): “Ein ägyptisches Dorf in Paris: eine empirische Studie zur SüdNord-Migration am Beispiel ägyptischer 'sans-papiers' in Frankrieich", in Michael Bommes (ed.): Transnationalismus und Kulturvergleich. Institut für Migrationsforschung und interkulturelle Studien, Osnabrück.

· Müller-Mahn, Detlef (2005): "Transnational Spaces and Migrant Networks: A Case Study of Egyptians in Paris", in Nord-Sud aktuell XIX, $2005 / 1$

- Nelson, Cynthia (1991): "Old Wine, New Bottles: Reflections and Projections Concerning Research on Women in Middle Eastern Studies", in Earl Sullivan \& Jacqueline Ismael (eds.): The Contemporary Study of the Arab World. University of Alberta Press, Alberta.

- Riccio, Bruno (2002): "Senegal is Our Home: The Anchored Nature of Senegalese Transnational Networks", in Nadje Al-Ali \& Khalid Koser (eds.): New Approaches to Migration? Transnational Communities and the Transformation of Home. Routledge: London and New York.

- Saad, Reem (2000): "Narratives of Faraway Experiences: Family and Styles of Manhood in an Egyptian Village". Paper submitted to The International Conference on Family History and Middle
East Studies, April 7-9. University of California, Berkeley.

- Salih, Ruba (2002): "Shifting Meanings of 'Home': Consumption and Identity in Moroccan Women's Transnational Practices between Italy and Morocco", in Nadje Al-Ali \& Khalid Koser (eds.): New Approaches to Migration? Transnational Communities and the Transformation of Home. Routledge, London and New York.

. The British Academy (2003): "Why Do Migrants Leave their Countries? Motivations to Migrate at the Point of Departure: The Case of Egypt" (2003): Final report for project. Co-ordinator: Dr Leila Simona Talani.

- Van Hear, Nicholas (2002): "Sustaining Societies under Strain: Remittances as a Form of Transnational Exchange in Sri Lanka and Ghana", in Nadje Al-Ali \& Khalid Koser (eds.): New Approaches to Migration? Transnational Communities and the Transformation of Home. Routledge, London and New York.

- Zohry, Ayman \& Harrell-Bond, Barbara (2003): "Contemporary Egyptian Migration: An Overview of Voluntary and Forced Migration". Country Background Papers. DRC Working Papers Series. http://www.migrationdrc.org/publications/work ing_papers.html

Reem Saad, research associate professor 